\title{
Giant duodenal ulcer: the hepatic intra-arterial chemotherapy variant
}

\author{
Eran Goldin, ${ }^{1}$ Tamar Peretz ${ }^{2}$ and Eugene Libson ${ }^{3}$
}

Departments of ${ }^{1}$ Gastroenterology, ${ }^{2}$ Radiation and Clinical Oncology and ${ }^{3}$ Radiology, Hadassah University Hospital, Hebrew University-Hadassah Medical School, IL-91120 Jerusalem, Israel.

\begin{abstract}
Summary: Giant duodenal ulcers are extensive ulcers, more than $2.5 \mathrm{~cm}$ in diameter, that involve a large portion of the duodenal bulb. These atypical duodenal ulcers create serious problems to the patient and the physician, are frequently complicated by bleeding and penetration, and have a high mortality rate. Most of the reported cases were classified as a severe variant of the common peptic ulcer disease, others were associated with the Zollinger Ellison syndrome. We report here four patients with giant duodenal ulcers but with a different and definitive aetiology: hepatic intra-arterial chemotherapy infusion for liver metastases or primary hepatocellular carcinoma.
\end{abstract}

\section{Introduction}

Giant duodenal ulcer is considered an atypical and dangerous variant of peptic ulcer disease. ${ }^{1,2}$ The diagnostic criteria are the extension of the ulcer - more than $2.5 \mathrm{~cm}$ in diameter - and the fact that about $80 \%$ of the bulb is involved in the ulcer cavity, ${ }^{3}$ predisposing to haemorrhage or perforation.

In the pre-endoscopic era, some cases were misdiagnosed by upper gastrointestinal X-ray series and confused with deformed bulbs or pseudodiverticula. $^{3}$ Today, combined X-ray and endoscopic studies make the diagnosis easier.

Treatment of liver metastases with hepatic intraarterial chemotherapy (HAIC), using a surgically implantable pump, has become a widespread method and was associated with improved clinical responses and survival.4,5 However, several gastrointestinal complications have been reported: erosions and ulcers in stomach and duodenum, ${ }^{6}$ biliary sclerosis ${ }^{7}$ and acalculous acute cholecystitis. ${ }^{8}$

We describe four non-peptic patients who received intra-arterial chemotherapy for liver metastases and who developed giant duodenal ulcers. Two of them died from severe gastrointestinal bleeding. We discuss this new aetiology for giant duodenal ulcers and stress the importance of a closer endoscopic follow-up of patients undergoing intra-arterial cytotoxic treatment for early detection of gastrointestinal damage.

Correspondence: E. Goldin M.D.

Accepted: 9 December 1987

\section{Materials and methods}

During the period from July 1982 to December 1986, 23 patients (18 with liver metastases and 5 with primary hepatocellular carcinoma) were treated in our hospital by a selective infusion of chemotherapeutic agents through a surgically implanted hepatic artery catheter and pump. None of them had a history of peptic ulcer. During laparotomy, the gastroduodenal artery and the right gastric artery were ligated to avoid perfusion of the stomach. The drugs we used were floxuridine (FUDR) by continuous infusion in combination with intra-arterial mitomycin-C bolus. Patients with primary hepatocellular carcinoma received a bolus of adriamycin instead of mitomycin-C. The patients were followed up and if any gastrointestinal complaints or symptoms appeared a gastroscopy or $\mathrm{X}$-ray series was performed.

\section{Results}

Ten patients experienced gastrointestinal problems or liver function disorders and underwent gastroscopy, upper X-ray studies or endoscopic retrograde cholangiography. In four of these patients, a giant duodenal ulcer was found. In two patients biliary sclerosis was diagnosed and in the others a moderate erosive duodenitis was disclosed by endoscopy. A clinical description of the patients with giant duodenal ulcer is presented in Table I. 
Table I Clinical details in giant duodenal ulcer patients

\begin{tabular}{|c|c|c|c|c|c|c|c|}
\hline Patient & Age & Sex & Diagnosis & $\begin{array}{l}\text { Liver } \\
\text { irradiation }\end{array}$ & $H A I C$ & $\begin{array}{c}\text { Time from } \\
\text { initial } \\
\text { infusion } \\
\text { to symptoms }\end{array}$ & $\begin{array}{c}\text { Gastrointestinal } \\
\text { symptoms }\end{array}$ \\
\hline 1 & 41 & $\mathbf{F}$ & $\begin{array}{l}\text { Breast carcinoma } \\
\text { Liver metastases }\end{array}$ & $2000 \mathrm{rad}$ & $\begin{array}{l}\text { Mitomycin-C } \\
\text { FUDR }\end{array}$ & 5 months & Epigastric pains \\
\hline 2 & 53 & $\mathbf{F}$ & $\begin{array}{l}\text { Colon carcinoma } \\
\text { Liver metastases }\end{array}$ & $2000 \mathrm{rad}$ & $\begin{array}{l}\text { Mitomycin-C } \\
\text { FUDR }\end{array}$ & 6 months & Bleeding \\
\hline 3 & 69 & $\mathbf{M}$ & $\begin{array}{l}\text { Primary } \\
\text { hepatocellular } \\
\text { carcinoma }\end{array}$ & None & $\begin{array}{l}\text { FUDR } \\
\text { Adriamycin }\end{array}$ & 5 months & Bleeding \\
\hline 4 & 74 & $\mathbf{M}$ & $\begin{array}{l}\text { Primary } \\
\text { hepatocellular } \\
\text { carcinoma }\end{array}$ & None & $\begin{array}{l}\text { FUDR } \\
\text { Adriamycin }\end{array}$ & 7 months & Bleeding \\
\hline
\end{tabular}

HAIC $=$ hepatic intra-arterial chemotherapy; FUDR = floxuridine.

They were two female patients with liver metastases (primaries: colon and breast) who were treated by liver irradiation (2000 rad) and received mitomycin$\mathrm{C}$ and FUDR by HAIC; and two male patients with primary hepatocellular carcinoma who received FUDR and adriamycin through the intraarterial pump. The interval between the initial dose of chemotherapy and the development of symptoms was variable, ranging from 5 to 7 months. The presenting symptom in three of the patients was upper gastrointestinal bleeding and in the remaining patient epigastric pain. Figure 1 shows an upper gastrointestinal X-ray of giant duodenal ulcer in patient no. 3. In all the patients, when the ulcer was diagnosed, chemotherapy was discontinued and anti-ulcer therapy with $\mathrm{H}_{2}$ blockers and sucralfate instituted.

Patients 3 and 4 died with severe bleeding 2 and 3 weeks after the diagnosis. Patients 1 and 2 stopped bleeding, the giant ulcer healed and they died 4 and 6 months later from reasons unrelated to this complication.

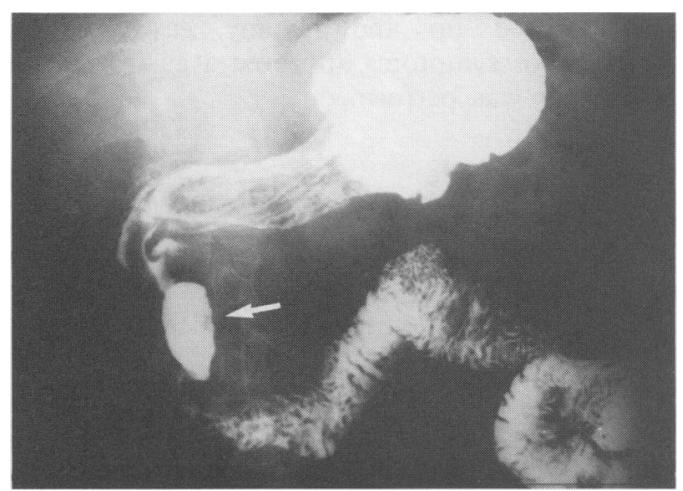

Figure 1 Upper gastrointestinal barium study showing a giant duodenal ulcer in patient 3 .

\section{Discussion}

Giant duodenal ulcers measure more than $2.5 \mathrm{~cm}$ in diameter. Usually they are on the posterior wall ${ }^{1-3}$ and are frequently complicated by bleeding and penetration. Also gastric outlet obstruction may occur.

Usually, giant duodenal ulcer is diagnosed after a long, typical, duodenal ulcer disease history, and till now was considered as a severe variant of common peptic ulcer disease. ${ }^{1,2}$ In Zollinger Ellison syndrome, some cases of giant duodenal ulcer were reported. ${ }^{9}$ One case was attributed to non-steroidal anti-inflammatory drug ingestion. ${ }^{3}$

We report here four cases of giant duodenal ulcer in patients receiving intra-arterial chemotherapy for liver metastases or primary hepatocellular carcinoma. This treatment, using a percutaneous catheter or a surgically implanted hepatic artery catheter and a pump, was associated with a response rate of $55-83 \% .^{4,5}$ Gastrointestinal complications had been described and included gastroduodenal ulceration, ${ }^{6}$ biliary sclerosis ${ }^{7}$ and acalculous cholecystitis. ${ }^{8}$ Giant duodenal ulcer was a frequent complication in our patients. We found only one clear description of a giant duodenal ulcer in previous publications. ${ }^{10}$

One explanation for these serious problems is an unavoidable infusion of the stomach and the duodenum via the gastroduodenal and right gastric arteries. On the other hand, when these arteries are ligated during laparotomy, as we did, a relative ischaemia may also cause damage of the mucosa. Another contributing factor could be the local perfusion of the duodenum by the drugs secreted through the hepatobiliary tract. ${ }^{7}$

In our series, we found that the most acute, lifethreatening gastrointestinal complication of the 
selective intra-arterial chemotherapy is giant duodenal ulcer. Two of our four patients with this complication died with massive bleeding. It is of interest that these two cases were primary hepatocellular carcinoma patients. Patt et al. ${ }^{11}$ reported selective intra-arterial infusion in this kind of patient, but did not describe such complications.

\section{References}

1. Klamer, T.W. \& Mahr, M.M. Giant duodenal ulcer: a dangerous variant of a common illness. Am J Surg 1978, 135: 760-762.

2. Soll, A.H. \& Isenberg, J.I. Duodenal ulcer diseases. In: Sleisenger, M. \& Fordtran, J.S. (eds) Gastrointestinal Disease, 3rd ed. W.B. Saunders, Philadelphia, 1983, p 652.

3. Eisenberg, R.L., Margulis, A.R. \& Moss, A.A. Giant duodenal ulcers. Gastrointest Radiol 1978, 2: 347-353.

4. Patt, Y.Z., Mavligit, G.M., Chuang, V.P. et al. Percutaneous hepatic arterial infusion of mitomycin-C and fluoroxidine: an effective treatment of metastatic colorectal carcinoma in the liver. Cancer 1980, 46: 261-265.

5. Balch, C.M., Urist, M.M., Soong, S.J. \& McGregor, M. A prospective phase II trial of continuous FUDR regional chemotherapy for colorectal metastases to the liver using a totally implantable drug infusion pump. Ann Surg 1983, 198: 567-573.

6. Wells, J.J., Nostrant, T.T., Wilson, J.A.P. \& Gyves, J.W. Gastroduodenal ulcerations in patients receiving selective hepatic artery infusion chemotherapy. Am J Gastroenterol 1985, 80: 425-429.
We conclude that giant duodenal ulcer may be induced in non-peptic patients by selective intraarterial infusion of chemotherapy for liver metastases. We stress the high mortality rate of this condition and recommend endoscopy before and after treatment, even in asymptomatic patients or those with mild, non-specific abdominal complaints.

7. Hohn, D., Melnick, J., Stagg, R. et al. Biliary sclerosis in patients receiving hepatic arterial infusions of floxuridine. J Clin Oncol 1985, 3: 89-102.

8. Lafon, P.C., Reed, K. \& Rosenthal, D. Acute cholecystitis associated with hepatic arterial infusion of floxuridine. Am J Surg 1985, 150: 687-689.

9. McGuigan, J.E. The Zollinger Ellison syndrome. In: Sleisinger, M. \& Fordtran, J.S. (eds) Gastrointestinal Disease, 3rd ed. W.B. Saunders, Philadelphia, 1983, p 696.

10. Crowley, M.L. Penetrating duodenal ulcer associated with an operatively implanted arterial chemotherapy infusion catheter. Gastroenterology 1982, 83: 118-120.

11. Patt, Y.Z., Chuang, V.P., Wallace, S., Benjamin, R.S., Fuana, R. \& Mavligit, G.M. Hepatic arterial chemotherapy and occlusion for palliation of primary hepatocellular and unknown primary neoplasms in the liver. Cancer 1983, 51: 1359-1363. 